\title{
LA PLAZA NUEVA y SU CASA CONCEJIL DONOSTIA-SAN SEBASTIAN 1715-1722 Creación de una pieza urbana modélica
}

\author{
José Javier PI CHEVROT \\ ENSAPLV - C.O.A.V.N \\ Director de Tesis: Ángel Martín Ramos \\ arkitektura@pichevrot.es
}

\section{RESUMEN}

Aquí se presenta una investigación sobre la creación, entre 1715 y 1722, de la Plaza Nueva de Donostia San Sebastián, mediante el vaciado de un espacio central en su tejido urbano "intra-muros". La Plaza con su Ayuntamiento y las casas que la circunvalan, se edificó siguiendo el diseño del arquitecto ingeniero, natural de Pavía, Hércules Torelli. Admirada y tomada como ejemplo por toda la provincia de Gipuzkoa, tendrá una gestión enteramente pública. Destruida y reconstruida, tras el asalto ingles de 1813, mantendrá su planta y volumen, conociéndose hoy como Plaza de la Constitución.

Palabras clave: Plaza Nueva, Casa Concejil, Donostia-San Sebastián, Hércules Torelli

\begin{abstract}
We present in this work our research about the creation, between 1715 and 1722, of the New Square of Donostia - San Sebastián, by emptying a central space in the urban fabric "intra-walls". The square, with its City Hall and the surrounding houses, was built according to the design of the engineer architect, Hercules Torelli, from Pavia, Italy. Admired and taken as a model throughout the province of Gipuzkoa, it will have an entirely public management. Destroyed and rebuilt after the English assault of 1813, it will keep its plan and volume, being known today as the Constitution Square.
\end{abstract}

Keywords: New Square, Town Hall, Donostia-San Sebastián, Hércules Torelli 


\section{INTRODUCCIÓN}

Al estudiar la historia del urbanismo donostiarra, la creación de la Plaza Nueva es el acontecimiento más relevante después de la fundación de la ciudad como villa y, quizás, de la formación orgánica de la Plaza Vieja con el doblamiento de las murallas, a principios del XVI. Fue una operación urbanística sin parangón, a comienzos del XVIII. El propósito era resolver una serie de problemas causados por la condición de San Sebastián de ser ciudad fronteriza militar, en cuanto al uso de la única plaza existente, la plaza que pasará a llamarse Plaza Vieja. La ciudad tomó la iniciativa de crear una nueva plaza para uso exclusivo de sus habitantes, con una nueva Casa Consistorial, a su vez Consular, al servicio de la burguesía comerciante, demostración de la pujanza de su economía. Paradójicamente, se concretó en una época de crisis, tras la Guerra de Sucesión Española. El encargado de semejante obra fue el "célebre" arquitecto ingeniero natural de Pavia, Hércules Torelli.

Dicha autoría ha sido reseñada con admiración por Llaguno y Amirola en la única obra escrita en el XVIII, aunque publicada a principios del XIX, que enumera las arquitecturas relevantes del país en esa época (Llaguno y Amirola, Noticias de los Arquitectos y Arquitectura de España... tomo I, p.89). En el Diccionario Geográfico-histórico de España, publicado en 1802 por la Real Academia de la Historia en Madrid, se recoge, casi con los mismos términos, la descripción halagadora de la Plaza Nueva y la autoría de Torelli, a pesar de ser censurado, el "follage" que adorna la casa consistorial. Así mismo, Camino y Orella en su Historia de la Ciudad de San Sebastián, escrita algunos años antes del incendio de 1813 reproduce casi textualmente lo expuesto en el diccionario de 1802, en ella la Plaza Nueva es "pulcra" y de "armoniosa simetría"; la Casa Consistorial es un "soberbio" edificio; la cual, en lo exterior no es del mas "refinado" gusto, por su "prolijo laboreo". Ayuntamiento y Plaza serán incendiados por las tropas inglesas de Wellington en 1813, y reconstruidos posteriormente. Hoy se conoce como Plaza de la Constitución.

\section{GÉNESIS}

En el estado actual de la investigación no existen documentos testimoniales directos y contemporáneos sobre la gestación del proyecto de la Plaza Nueva y su edificio Concejil y Consular. El incendio del propio ayuntamiento con sus archivos en 1813 no tendría que ser la única causa de semejante vacío documental. La corte de Madrid estuvo implicada necesariamente y se enviaron informes con los planos correspondientes. Se sabe que parte del archivo de Simancas, que podría corresponder al primer cuarto del XVIII y en el que pudieran estar dichos informes, desapareció en un incendio fortuito acaecido en noviembre de 1939, y no hay que excluir robos y deterioros múltiples.

Sin embargo, en los archivos provinciales de Gipuzkoa, tanto en el General sito en Tolosa (AGG) como en el de Protocolos de Oñati (AHPG), existen algunos documentos que aportan indirectamente datos de interés sobre la Plaza Nueva. El primero está repertoriado como AHPG-GPAH 2-0546, corresponde al protocolo de Azpeitia y está fechado el 11 de mayo de 1720. El documento formaliza, por parte de Joseph Antonio de Aguirre y Oquendo, marqués de San Millán y alcalde de San Sebastián, la demanda de un censo, es decir un préstamo, para ejecutar el proyecto de Plaza Nueva, que se hace al convento de la Concepción de Azpeitia. En el documento se transcribe la propuesta de censo hecha en San Sebastian el 8 de mayo y, sobre todo, el decreto que oficializa la decisión de crear una Plaza Mayor en la ciudad, redactado el 14 de septiembre de 1715. En dicho decreto están incluidas las razones por las cuales se toma semejante decisión y las formas de financiación de la operación. Se indica que el proyecto de la Plaza Mayor se ha escogido entre dos propuestas aportadas por "Ercules Turelli, inxeniero militar".

Se señala, además, que se aprobó una primera resolución, en convocatoria de "aiuntamiento General de Vezinos especiales", un 24 de diciembre del año de 1714, resolución que visiblemente ordenaba estudiar la creación de una Plaza Nueva; que el día 7 de septiembre de 1715 se encomendó a los regidores Juan Francisco de Llatazo, Simón de Celarain y Pedro Antonio de Lazcano examinar los planos con las dos alternativas ideadas por Torelli, y que se preparó a continuación una reunión el día 11 de septiembre, donde se expusieron las conclusiones del examen y en la cual se tomó la decisión definitiva, encargándose la redacción del decreto subsiguiente. Dicho decreto es el que se leería en "Junta y Reximiento de los Cavalleros hixosdalgo desta dicha Ciudad", el 14 de septiembre de 1715, que transcribirá el "escrivano de Su Magestad", público del Cabildo, Miguel de Eguzquiza. Para rematar el proceso consultivo y electivo, se señala que se realizaría una última "deliverazión en asumpto tan 
importante" mediante la convocatoria para el día 21 de septiembre de 1715, de un "aiuntamiento General de Vezinos especiales", tal como estaba previsto en la resolución del 24 de diciembre del año anterior. En este se leería el decreto "para la mejor inteligencia de vezinos", y se pondría de "manifiesto dichas planttas", pasándose después al voto.

En la asamblea general de vecinos especiales celebrada el 21 de septiembre de 1715 se aprobó por unanimidad el decreto del 14 de septiembre, con el proyecto de Torelli escogido y las modalidades de su ejecución. El 10 de octubre del mismo año, los apoderados del Ayuntamiento, Aguirre y Oquendo, Llatazo, Arrivillaga, Iriarte y Vildosola nombran los agrimensores y alarifes para proceder a la "abaluacion y examen" de las casas y suelos a comprar y expropiar, a saber Domingo de Leiza, Manuel Enrique Larena y Joseph de Semeroia, maestros cantero, carpintero y albañil, respectivamente. Las mediciones y valoraciones así ordenadas y las "pagas" correspondientes no debieron de demorarse mucho, porque en el mes de marzo del año siguiente ya se estaban derribando las casas. Hubo algunas protestas y pedimentos de personas que tenían algún interés o participación en las propiedades de la zona a demoler. Los demandantes consiguieron obtener del Consejo Real de Castilla un auto fechado el 13 de marzo de 1716 en el que dicho Consejo pedía informes y clarificaciones al ayuntamiento sobre el proyecto de la Plaza Nueva, debiéndose paralizar las obras mientras el mismo no tomara una decisión firme. Paralización que se confirmó en una carta expedida el 1 de abril del mismo año. Habría que esperar un año para que el Consejo Real se decantase definitivamente a favor de la continuidad de las obras, cursando una Real Facultad en ese sentido el día 19 de abril de 1717. Sin embargo, parece que el Ayuntamiento de San Sebastián no hizo mucho caso a los autos provisorios. Continuó, a pesar de todo, con los derribos y vaciados para poder acometer las obras de construcción que se iniciaron el 18 de junio de 1717. Todo ello se sabe gracias a dos expedientes encontrados en el Archivo General de Gipuzkoa.

El primer expediente, que podría haber provocado los autos del Consejo Real, gira alrededor del Pedimento hecho por Sebastian de Zuaznabar en representación de Cathalina de Tellería, y otros vecinos de San Sebastián, y fechado el 24 de Marzo de 1716 (AGG-GAO, COLCI 1740). Enfrentadas a la muy noble y muy leal Ciudad de San Sebastian, dichas personas se quejaban de no haber sido consultadas ni haber recibido justificación alguna ante el futuro derribo de unas casas, en principio, de su propiedad, "por solo aver hecho el examen su valor". Pedían que se recondujera la expropiación forzosa, protestando por no haber participado en la valoración de la indemnización, ni pactado la "forma i los plazos p(ar)a la paga". Alegaban sobre todo el que se procediese a derribar dichas casas para ser sustituidas por otras que "no son edificios públicos", en el "contorno" de la plaza.

Se adjunta en el expediente varios testimonios entre ellos uno del 26 de marzo, donde consta que el alcalde requirió al carpintero Martín de Miquelarena suspender la demolición de la casa vecina a la de doña Cathalina, sita en la calle Iñigo, que por ello amenazaba ruina. En dicho testimonio, como coletilla, se añadía que después del requerimiento, "el mismo dia prosiguieron en la demolición de las casas inmediatas vezinales". El 30 de Marzo de 1716, la queja se transforma en alarma al constatar el efectivo derribo de las casas que han de ser sustituidas, a pesar del auto suspensivo del Rey. Los demandantes protestan en vano. Les han llegado informaciones de que los nombrados por la Ciudad quieren acelerar los derribos para hacer inútil cualquier decisión de la Corte, imponiéndose los hechos consumados. La Ciudad argumenta que los derechos de propiedad que tienen los demandantes sobre las casas afectadas son mínimos e irrelevantes y que todo se ha hecho en pos del bien publico y con el acuerdo de todos, salvo "las partes contrarias queriendo singularizarse" de los "hixos y vezinos de dicha Ciudad", que han manifestado "el afecto de hixos a su patria" apoyando "una obra tan publica y necesaria ... para la mantenzion de su decoro".

En este expediente, aparece otro documento interesante, cual es el nombramiento de los peritos encargados de las evaluaciones de las casas a derribar y de los solares a expropiar, a la sazón Domingo de Leiza, Manuel Enrique Larena y Joseph de Semeroia, maestros cantero, carpintero y albañil. En el se invoca V(uesa) M(agestad) a quien se pide y suplica "se sirva mandar" a los referidos "agrimensores y alarifes", o sea los peritos, ejecutar su misión. Todo hace pensar que ello es solo una simple formula, más retórica que real, pues la Ciudad ni informó ni solicitó a la Corte de Madrid permiso para llevar a cabo las obras de la Plaza Nueva, tal como lo corroboran los hechos, los autos suspensivos del Rey y un informe posterior del corregidor Cano Mucientes (ver sección 4). 


\section{3 - "ABALUACIÓN" Y EXPROPIACIÓN}

El segundo expediente del Archivo General de Gipuzkoa, fechado en 1801, (AGG-GAO, CO ECI 4911), contiene la evaluación de una propiedad a expropiar y una copia de la Real Facultad emitida el 19 de abril de 1717 por el Consejo Real de Castilla, permitiendo la continuación de las obras. La evaluación pormenorizada de la propiedad referida, que totalizaba 26.118 reales, permite conocer indirectamente el tipo constructivo de una casa urbana donostiarra al comienzo del XVIII, así como una valoración de los precios relativos del suelo y de las partidas de la edificación en 1717.

Según estas partidas dicha casa urbana donostiarra debía de tener una cierta prestancia. La parte de la cantería era importante, los suelos, al menos de la planta baja, eran de losas de piedra y presumiblemente gran parte de los muros que daban a las calles eran de sillares de piedra. El maestro carpintero se revela como el personaje más importante, un verdadero contratista; junto al cantero, es quien se encarga de las mediciones; es el responsable de los forjados, de los postes, escaleras, de los entramados de fachada cuando los haya, y de la cubierta con sus tejas. Para él, realizar y controlar el replanteo del edificio es parte fundamental de su oficio. Aunque también se ocupa de las partes menores, de la "menuceria", que hoy en día se llama carpintería a secas. Los balcones, en su estructura, jabalcones y barandilla, los realiza el "errero", y no falta un escultor para colocar los escudos de armas de rigor. Todos estos maestros constructores, puestos por los "nombrados" del ayuntamiento, participarán, sin lugar a dudas, en las obras venideras del conjunto de la Plaza Nueva. Por último es interesante constatar que el valor del suelo, sumando el libre y el edificado, representa el $40 \%$ del conjunto del valor del solar con su casa.

Otro dato importante que se puede deducir de esta evaluación, es que su ámbito abarca todo el solar gótico, que se extiende, en este caso, al sur de la zona de intervención, de la calle Puyuelo a la calle Amasorrain, con un fondo total de entre 22 y 24 metros. Pero solo deviene público una mitad del solar, la parte trasera, donde generalmente se ubican los jardines y los "suelos vacios", que limita con la belena de Amasorrain, callejuela que desaparece para dar paso al frente sur de la Plaza. La naturaleza exacta de los procesos de expropiación llevados a cabo es un interrogante. ¿La Ciudad compró los solares al completo, con sus casas, para después derribarlas y vender la parte destinada a ser propiedad privada afín de reconstruirlas, tal como parece indicar lo acontecido con el solar de este expediente?, o cabría también la posibilidad de que los propietarios se quedaran con dicha parte privada, manteniéndose o no la casa original. La coyuntura puede cambiar si la parte a expropiar es la trasera, con suelos vacíos, como en la manzana sur, o la parte delantera, donde se sitúan las casas, necesariamente condenadas, como en la manzana norte, donde quedan privadas y edificables las partes traseras. En la manzana central la disyuntiva no se plantea al desaparecer enteramente los solares en beneficio de la Casa Concejil y del propio espacio libre de la Plaza.

En todo caso, aunque permaneciesen algunas casas privadas en los solares afectados por las expropiaciones, se puede pensar que la operación urbanística de la plaza nueva también implicó una renovación de las casas y un aumento de la densidad edificatoria del entorno cercano. Sin lugar a dudas, muchos propietarios y la propia Ciudad salieron beneficiados por estos negocios perimetrales, añadidos y complementarios.

En este expediente de 1801, después de haber establecido la evaluación, se especifican los modos de la "paga" a cargo de los señores "poder havientes y nombrados", encabezados por el propio alcalde Aguirre y Oquendo. La "paga" se reparte entre fundaciones à censo, liquidación de censos, distribuidos entre varios estamentos eclesiásticos y civiles de la provincia y restituciones al mayorazgo detentor de la propiedad comprada. Se insiste que "las dichas casas con sus suelos, quartos, edificios y fabrica y suelos vacíos expresados, aires y cielos (derecho a ventilación y vista) correspondientes à ellos, entrada y salida, derechos y servidumbres" deben en "cualquiera manera" quedar "libres de maiorazgo, censo perpettuo", "ni otra carga ni obligación general ni particular, ni hipoteca". Se considera que se ha establecido el "justo precio" y "si más valen", "de la demasía y más valor, sea en poca ò mucha cantidad" se ha de hacer donación a la ciudad de San Sebastián. 


\section{4 - CONTEXTUALIZACIÓN, EDIFICACIÓN Y ORDENANZAS.}

En el decreto del 14 de septiembre de 1715 se explicitan las justificaciones y principios de la operación, como la necesidad de tener una plaza propia, sin interferencia militar y la oportunidad de dotarse de una nueva casa concejil; los principios esgrimidos son rapidez de ejecución, economía, belleza, desahogo y utilidad.

Los inconvenientes que tenía la plaza que pasará a llamarse Vieja, una vez se construya la Nueva, eran múltiples y variados. Empezando por su situación, a la entrada de la ciudad, formalizando un espacio residual, antes exterior, que deviene interno en tiempos de Carlos V, al erigirse la cortina sur con su puerta de tierra. Dicha Plaza Vieja, no era una creación diseñada según las reglas de la geometría, sino una tierra de nadie, entre murallas nuevas y edificios improvisados, cubriendo las murallas viejas. Era un espacio compartido entre los vecinos de la Ciudad y la guarnición militar con varios cuarteles en los aledaños. La existencia cercana de un Café y de varias tabernas, con clientela sobre todo militar, hacían poco frecuentable la zona para la burguesía donostiarra. La situación empeoraba cuando se celebraban festejos y corridas de toros. La mezcla entre la soldadesca, venida del exterior y las gentes del pueblo, pescadora y marinera "tan crecida y belicosa" provocaba chispas. De no ser por la intervención de los alcaldes y de diversos eclesiásticos, un enfrentamiento ocurrido en 1713 podría haber acabado con muertos. Así mismo, se hacía dificil la asistencia a las corridas de toros y demas espectáculos, por ser la plaza estrecha. La Ciudad perdía así una importante fuente de ingresos. El uso racional de una plaza rectangular, como la Plaza Nueva, con balcones corridos, remediará esta restricción y permitirá celebrar y explotar ventajosamente todo tipo de espectáculos, añadiendo rentabilidad financiera a la operación. Los regidores de la ciudad, mas allá de las "indecencias" y de las fricciones entre gentes opuestas, no podían tolerar que los militares podíeran disponer a su antojo de la Plaza Vieja para sacar los soldados a "exquadronar". Ello era contraproducente para el comercio, como el de la venta de frutas y verduras por parte de las "recattonas" que los militares a penas toleraban y que la ciudad no podía controlar. La creación de la nueva Plaza supondrá, la reconducción del comercio en un sitio mas adecuado, céntrico y funcional con sus oportunos y aprovechables soportales.

Céntrica era la ubicación escogida para la nueva plaza. Dicha elección resolvía, además, el problema del adecentamiento de una zona urbana degradada, cuyas casas eran muy "biexas y arruinadas" y cuyos solares estaban a veces vacíos y abandonados. La operación creadora de una nueva centralidad, de un nuevo espacio de uso y esparcimiento, con la recomposición de una nueva jerarquía edificada, apoyada en el nuevo edificio concejil, resultaba ser, al mismo tiempo, una operación de regeneración urbana.

Para la corporación donostiarra es vital la "prompta execucion de ttan importtante obra". Entre la decisión de estudiar y realizar un proyecto de plaza, tomada en asamblea general de vecinos especiales, el 24 de diciembre de 1714, y la aprobación de dicho proyecto, redactado por Hércules Torelli, en una segunda asamblea de las mismas características, el 21 de septiembre de 1715, solo transcurren 9 meses. En octubre se nombran los peritos que han de examinar y valorar las propiedades a expropiar y comprar. Estos cumplen con celeridad su cometido para pasar a efectuarse las compras, y ya en febrero o marzo de 1716 comienzan los derribos. Se iniciaran las obras de construcción de las casas un año y cuatro meses después, el 18 de junio de 1717, una verdadera hazaña, si se tiene en cuenta el complejo proceso de demandas de censos o préstamos para financiar la operación y los medios limitados de la época para el derribo, la explanación y la urbanización del vaciado. Se debió de movilizar una gran cantidad de operarios para llevar a cabo, con celeridad, un trabajo de semejante amplitud.

La Ciudad no perdió el tiempo en comunicar a la Corte de Madrid su intención de construir una Plaza Nueva, ni en peticionar el permiso correspondiente. Esta "ligereza" procesal por parte de los regidores donostiarras esta confirmada por el corregidor comisionado por la corte en la provincia de Gipuzkoa del año 1753 al año 1756, Don Pedro Cano y Mucientes, en su libro "Ordenanzas de Gobierno, método de distribuir Propios, y Arbitrios de la Ciudad de San Sebastian, 1760", p.359: “... En virtud de estos Decretos principiaron los Apoderados de la fabrica, tomando sobre Propios de la Ciudad, y bienes de los Vecinos, que concurrieron à ellos, hasta en cantidad de (10.658) ducados, ocho reales y un maravedi, sin Real facultad..."

Los autos suspensivos del Consejo Real de Castilla, que tenía que haber aprobado el proyecto, en particular la demanda de censos o préstamos, no se obedecieron, al menos en un primer momento y seguramente en 
su generalidad. Seria el episodio de la toma de la ciudad por el duque de Berwick, en julio de 1719, el que alteraría el curso de las obras, sobre todo si consideramos que la guerra y la ocupación francesa que finalizo en agosto de 1721, supusieron considerables gastos financieros. La desviación de buena parte de los materiales constructivos, como vigas y maderos, para reutilizarlos como cortaduras y barricadas en la defensa de la ciudad, tampoco ayudó. (Camino y Orella, historia de San Sebastián ed.1923, p.292). Sin embargo teniendo en cuenta que la plaza y los edificios que le "circunvalaban" se terminaron de construir el 18 de enero de 1722 (Archivo Municipal de San Sebastián, expte 1759-2), se puede decir que el esfuerzo emprendido fue de una gran eficacia. Entre tres y cuatro años hay que estimar el tiempo efectivo de las obras de edificación. La determinación de llevar a cabo la construcción de la Plaza Nueva lo más rápidamente posible era muestra de la seguridad que tenían los vecinos donostiarras de que aportaban a la ciudad "ermosura y desaogo", estética y funcionalidad.

El proyecto se presentó con dos variantes. La primera planteaba una plaza que medía $90 \times 62$ codos es decir 50,22 x 34,60 metros, con la Casa Concejil, en el lado Norte, entre viviendas, con 24 casas de 10 codos de frente, o sea dos huecos a fachada, y un coste de 66.000 ducados de plata, sin incluir el edificio Concejil. En la segunda variante, las medidas eran algo superiores, de $95 \times 70$ codos, es decir, 53,01 x 39,01 metros, con la Casa Concejil exenta, en el costado Oeste, y con un coste superior. Se escogió la primera solución, la más económica y quizás la más evidente, con la fachada del Ayuntamiento mirando hacia el sur, como era el caso de las iglesias de Santa María, de Santa Ana, hoy Santa Teresa, y de la de San Telmo. Sin embargo, la que se construirá será la segunda variante, con 25 casas, también de 10 codos de frente, salvo las tres del lado Este, y con medidas ligeramente diferentes, de unos 55,00 x 37,00 metros; el coste final será, sin considerar el edificio Concejil, de 97.288 ducados de plata. Probablemente, estos cambios se plasmaron en los decretos emitidos por la ciudad en fecha de 1 de junio, 14 de junio y 18 de junio de 1717, que resolvían las últimas "dudas", previo a la colocación de la primera piedra, de los cuales, como del coste final, hay constancia en el libro de Cano y Mucientes, "Ordenanzas...",p.361, pero cuyos contenidos, de momento, se desconocen.

La Plaza Nueva se consigue vaciando un espacio comprendido entre la calle Iñigo y la callejuela o belena Amosarrain. Las medidas definitivas de la Plaza se han deducido del levantamiento de los solares realizado por el arquitecto Pedro Manuel de Ugartemendia tras el incendio de 1813. Se acercan a la ratio ideal de 1,5:1, y serán casi las mismas que las de la Plaza reconstruida, es decir la Plaza actual, de 57,48 m por unos 38 metros.

Queda por saber cuando y como se requirió la participación de Torelli, si las dos alternativas las propuso el arquitecto italiano por iniciativa propia, o si eran dos ideas que habían barajado los regidores y que estos le pidieron que estudiara. La relación de Torelli con su ciudad de adopción tenía que ser por aquellas fechas excelente, para que esta le encargue un proyecto tan transcendental. La reforma del convento de las Agustinas de San Bartolomé, las obras de restauración y ampliación de las fortificaciones de la ciudad y de su castillo (Llaguno y Amirola, Noticias..., p.89-90), pero también otros presumibles proyectos que hoy en día están olvidados, obraron seguramente en su favor.

El emplazamiento de la Plaza, sus medidas, la situación del Ayuntamiento, el número de arcos, con sus dimensiones, incluso la numeración pintada en negro en los cabezales de cada hueco de las casas, para facilitar el alquiler de los balcones en caso de festejos, se repetirán en la reconstrucción llevada a cabo por Pedro Manuel de Ugartemendia a partir de 1817, tras el incendio de 1813. En un expediente fechado en 22 de Mayo de 1816, guardado en el archivo provincial de protocolos de Oñati y relacionado con la casa numero 4 de la Plaza Nueva (AHPG-GPAH 3-0119), figuran en las escrituras de su venta, que la Ciudad tuvo que realizar por fuerza mayor en febrero de 1810, las ordenanzas que cada una de las 25 casas de la Plaza Nueva debía de cumplir desde el principio y que se mantuvieron al pasar de la propiedad pública a la privada. Resumiendo, en la ordenanza $1^{\mathrm{a}}$ se recalcaba la propiedad municipal de los soportales de la plaza; en la $2^{\mathrm{a}}$, lo mismo para los balcones, que podian ser alquilados por el ayuntamiento en caso de festejos; en la $3^{\mathrm{a}}$ se obligaba a los residentes a iluminar los balcones con "Achas" o gruesas velas, cuando asi se les indicara; en la $4^{a}$ se prescribía la unicidad e invariabilidad del diseño simétrico de las fachadas de las casas; en la $5^{a}$ se especificaba como disponer y pintar en los balcones un rodapie de "celosía", manteniendo siempre una estricta igualdad y simetria; en la $6^{\mathrm{a}}$ se imponían normas de salubridad e higiene relativas a los productos que se pudieran vender en las "cabañas" o locales de los bajos; en la $8^{a}$ se prohibía la colocación de tiestos y cualquier otro objeto en los balcones; y en la $9^{a}$ se especificaba como pintar y mantener los elementos y las paredes de la fachada, así como los "rafes" o aleros. 
Existe en el archivo general de Gipuzkoa, en Tolosa, un expediente AGGCOLEJ 1505_00-59 fechado en 1722, que se refiere a un juicio cuyo punto de partida es una almoneda realizada el 23 de Agosto de 1718. Explicita que condiciones y calidades, la Ciudad pide a los Maestros Carpinteros para obtener el encargo de "la manifatura de todas las obras de carpintería de las casas nuevas consistoriales y concejiles que ... estan ejecutando en su plaza maior y de las tres (a)ceras de casas que tambien estan ejecutando en la circunvalación de dicha plaza". La Ciudad se comprometía a aportar el maderamen necesario a pie de obra, al ser propietaria de terrenos arbolados. Los regidores intentan abaratar a lo máximo los costes de la "manifactura", es decir de la mano de obra. Para ello se juntaba en una sola persona la adjudicación de la totalidad de la dicha obra de carpintería, para que se puje a la baja y así evitar repartos y acuerdos entre los maestros carpinteros en el caso de que se hubiera subastado lote por lote, dividiendo los trabajos en varias partes y fases. Se supone que se han utilizado los mismos métodos para otorgar toda la cantería, toda la albañilería, toda la herrería, etc a un solo maestro cantero, maestro albañil, maestro herrero, etc. Y el plazo que la Ciudad daba para finiquitar dichas obras era solo de año y medio.

La economía de medios era uno de los ejes que condicionaba el proyecto de la Plaza. Además de utilizar materiales propios como el maderamen y reducir los precios de la mano de obra mediante subasta, la Ciudad preconizaba la reutilización de materiales provenientes de los derribos, como la "Ripia Viexa" sobre la cual se asentaban las tejas de la cubierta. Otra de las condiciones impuestas al rematante ganador de la almoneda era la de imponerle unas fianzas elevadas, aportadas por socios, lo que provocaba fuertes endeudamientos, sobre todo si había que subcontratar a otros carpinteros, al no poder abarcar toda la obra. Se creaban así una cadena de dependencias financieras difíciles de controlar, y cuando uno de los eslabones fallaba, se podían producir paralizaciones, impagos y pleitos, como en el caso de este expediente.

\section{5 - ANALISIS}

La disposición de las 25 casas era muy racional, y partiendo de los planos parcelarios dibujados por Pedro Manuel Ugartemendia, se ha podido restituir a grosso modo su tipología original. San Sebastian intramuros tenia limitada su superficie habitable y el proyecto de las casas "que han de circunvalar la plaza" se realizó apurando a lo máximo las medidas de sus plantas, en un ejercicio que hoy llamaríamos minimalista, y que el propio Ugartemendia censuró, tildando dichas casas de estrechas y poco iluminadas. Las parcelas góticas preexistentes se dividieron en dos, una tendencia que también se generalizó en otras partes de la Ciudad, pero no de una manera conjunta y ordenada como aquí. Los propietarios aprovecharían oportunamente la situación para densificar, renovar y aumentar las alturas de sus bienes edilicios en las partes que permanecieron privadas, compensando de alguna manera la reducción de sus solares. La ocupación edificada deviene total y desaparecen jardines y espacios libres. Las partes traseras de las casas de propiedad municipal se ven adosadas a las que son de propiedad privada y la iluminación y ventilación de ambas se resuelven, difícilmente, mediante patinillos.

Las medias parcelas perimetrales de propiedad privada, permanecieron con sus divisorias originales irregulares. Por el contrario las nuevas parcelas publicas, bordeando la plaza, seguían un diseño uniformizador, tenían todas el mismo ancho de 10 codos, es decir de 5,58 m, la distancia verdaderamente limite que pueda permitir la ubicación de dos huecos por vivienda de unos 2,50 $\mathrm{m}$ libres cada uno, que a su vez correspondían a un entre eje de 2,79 m para los arcos de los soportales. La escala es reducida y podría parecer insuficiente sino fuera que la sobriedad de los elementos y su repetición sistemática confieren al conjunto una serena magnificencia. Existían las excepciones de las parcelas de las esquinas, un poco más anchas, por la necesidad del diseño, y de las parcelas de la parte este, enfrentada a la casa concejil para las cuales Torelli optó por un frente de tres huecos y de tres arcos por parcela, pero guardando el mismo entre eje. Las fachadas longitudinales disponían de 20 arcos y huecos abiertos a la Plaza que correspondían a 11 casas, de las cuales, las extremas tenían el último hueco y arco retranqueados en el ámbito del soportal; la fachada transversal de casas presentaba 9 arcos y huecos enteramente abiertos añadiendo tres nuevas casas, siendo la central más pequeña que las otras dos laterales. Lo que sumando, alcanza la consabida cifra de 25 casas.

En cambio la uniformidad de las dimensiones de los fondos de las nuevas parcelas públicas es algo más relativa, y si bien las líneas de separación con la parte no pública son rectas y continúas, estas se adaptan al ancho de las manzanas intervenidas. En la manzana norte la línea divisoria se va abriendo de oeste a 
este para así mantener una cierta proporcionalidad entre la parte pública y la parte privada. El fondo medio es en este caso de unos $14,50 \mathrm{~m}$ para la nueva parcela, a la que le sigue por detrás unos 12,80m de parcelario antiguo. En la manzana sur, mas regular, la línea medianera es completamente paralela con la alineación de la Plaza, y casi paralela a las fachadas de las casas privadas que dan a la calle Puyuelo. El fondo es aquí igual para todas las parcelas de propiedad municipal, es decir de unos 11,40 m, con un fondo yuxtapuesto de unos $11 \mathrm{~m}$ para las parcelas privadas. En cuanto a las tres parcelas restantes en el lateral de la Plaza, la medida de su fondo es aun menor, de unos 9,10 m, compensado, eso si, por el hecho de que disponen de un hueco más a la plaza. Las superficies de las plantas construidas resultantes, todas del mismo modelo, son consecuentemente mínimas, partiendo de los $64 \mathrm{~m} 2$ de la parte sur, hasta los $78-93 \mathrm{~m} 2$ del frente lateral, pasando por los $81 \mathrm{~m} 2$ de la parte norte. La planta baja y la entreplanta se ven reducidas por el área que ocupan los soportales cuyo fondo interior es de unos 4,20m en todo el contorno de la Plaza, salvo en el lado de la Casa Concejil. Por encima se han levantado tres plantas mas una bajo cubierta, con una serie de "guardillas" o buhardillas acopladas de dos en dos y dejando un espacio libre entre cada par. Las escaleras eran de un solo tramo, en la parte trasera, estrechas y empinadas para salvar una altura media de unos 3,30 m, algo menor en la planta baja y en la entreplanta. Hay que tener en cuenta que no existían entonces cajas de escaleras propiamente dichas y que hasta mediados del siglo XIX las casas humildes y las que no eran ni palacios, ni palacetes carecían por completo de privacidad. El acceso publico a los balcones, para asistir a los festejos y a las corridas de toros, se hacía sin objeción alguna a través de las habitaciones "privadas".

En el poniente de la plaza se erguía majestuoso el ayuntamiento, también de piedra arenisca labrada, aunque con elementos decorativos añadidos de Mármol blanco. Su planta era cuasi cuadrangular con un frente de 23,40 $\mathrm{m}$ y un costado de 19,12 $\mathrm{m}$. El fondo de sus soportales, de $8,25 \mathrm{~m}$, era bastante mayor que en el resto de la plaza, casi el doble. Correspondía al fondo de las dos salas, de la Ciudad en la primera planta y del Consulado en la segunda, que ocupaban todo el frente de la plaza. Igualmente más amplios, con un entre eje de unos 4,20m, se presentaban sus cinco arcos. Esta amplitud confería al edificio una adecuada ascendencia jerárquica sobre las demás construcciones, ascendencia reafirmada por unos pisos más altos y una cornisa que dominaba todas las otras. Tildado de "churrigueresco" por algunos, el ayuntamiento respetaba, sin embargo, unas proporciones equilibradas, neoclásicas, de cinco crujías conformadas por los cinco arcos antes citados y que resaltaban, gracias a unas elegantes balconadas de herrería recubierta de dorado, un triangulo central. El edificio, verdadero palacio italiano, disponía en su cubierta de una galería abalaustrada ritmada por una serie de pebeteros barrocos, que se interrumpía, en su centro, ante un frontón triangular, bajo el cual se reservaba un espacio significativo para el escudo de la ciudad, acompañado a ambos lados por dos fieros leones, todo ello en mármol de la república de Genova, seguramente de Carrara. Y en la coronación de dicho frontón, yacía un grupo escultórico impactante, de alabastro, formado por las figuras de la Justicia y de la Prudencia. Los ejes verticales entre crujía y crujía, así como las jambas de las puertas ventanas, estaban finamente decorados por un encaje de piedra "florido", juzgado excesivo al comienzo del siglo XIX, pero que distaba mucho de la decoración recargada de un Churriguera.

Hércules Torelli juega con el contraste entre la rica y delicada decoración del edificio concejil y la rotunda sencillez del resto. También diferencia claramente la escala del ayuntamiento con su función representativa, de la escala, proporcionalmente menor, de los edificios residenciales, que forman una $U$ homogénea, alrededor de la Casa Consistorial. Ambos elementos se refuerzan y adquieren, así, más valor y profundidad en un espacio que no deja de ser reducido y que se asemeja más al patio de un gran palacio que a una Plaza Mayor, cuyas dimensiones de ancho y largo habría que multiplicar por dos o mas, cuando consideramos las de Madrid, Valladolid o Salamanca. La Casa Consistorial, a su vez sede del consulado fue, al igual que la Plaza, muy apreciada por los donostiarras y admirada en el resto de la provincia. En los testimonios escritos de los viajeros del siglo XVIII, los elogios son constantes. Incluso Ugartemendía, juzgó que la Casa Consistorial de Torelli era un "edificio bastante capaz y de excelentes salones" con un "soportal o arcada espaciosa", empero denigró su fachada, reprochando su aspecto "churrigueresco". Sirvió de ejemplo y modelo a la hora de dotarse de nuevos ayuntamientos las villas y pueblos de Gipuzkoa. Las influencias se pueden notar en los de Elgoibar (1737), Astigarraga (1743), Asteasu (1747), Hernialde (1753), Arrasate-Mondragón (1755), etc. Quizás el ejemplo más claro sea el del ayuntamiento de Oñate (1761).

Silvestre Pérez y Ugartemendía, cuando reconstruyen el Ayuntamiento y la plaza, intentan reconducir dicho contraste. Los frentes de los edificios de viviendas guardaran las mismas características, pero como rechazan la semántica barroca, sustituyen, en la fachada del edificio consistorial, la decoración extremadamente elaborada y estudiada de Torelli, por la ampulosidad monumental, con voluntad de 
austeridad, de las columnas dóricas. El edificio pierde legibilidad. La verticalidad de la decoración barroca, suavemente sugerida, estaba felizmente rematada con los pebeteros de la coronación y aportaba ligereza y fluidez a la fachada del primer ayuntamiento. En cambio, la verticalidad demasiado subrayada de la del segundo se ve truncada por un dintel y una cornisa, ambos exagerados, que relegan el escudo y los símbolos municipales a un segundo plano, perdiendo así la centralidad y el fantástico protagonismo que tenían anteriormente. Como pierden protagonismo y distinción el balconaje, comido y arrinconado por las columnas, y los cinco arcos que se ven retraídos a la mismas medidas que los del resto de la Plaza. Los soportales del edificio público reconstruido están condicionados por la carga, más formal y artificial que real, de la columnata que impone gruesos machones. En vez de ser abiertos, acogedores y una verdadera escenificación de la entrada, tal como lo planteó Torelli, son oscuros, desagradables y pasan desapercibidos. Silvestre Pérez y Ugartemendía eran hijos de la llustración, pero, paradójicamente, en sus intenciones conceptuales estaba el propósito de valorar, diferenciar y separar del tejido urbano los centros de poder, tanto político, como religioso. Ugartemendía obró de manera parecida con la Iglesia de Santa María, desarticulando su atrio. Al contrario, el barroco de Torelli se integraba en el tejido urbano medieval de la ciudad intramuros donostiarra, era un palacete más, entre los muchos y variados que la puntuaban y enriquecían, eso si, el más grande y elegante, con la perspectiva de la nueva plaza por delante.

Existe sólo de una imagen de la plaza y del ayuntamiento de Torelli, un grabado un poco "naif", sin el no se hubiera podido hacer este estudio comparativo, ni el análisis formal de dichos elementos. Un capitulo importante y significativo de la historia de la Arquitectura y del Urbanismo de San Sebastian, y no solo, hubiera desaparecido como tal y se hubiera quedado en una crónica donostiarra más. La figura de Hércules Torelli se habría difuminado un poco más en el olvido.

Queda la duda de cómo Torelli resolvió el lado este de la plaza. En el lado oeste, en las esquinas, a ambos lados del Ayuntamiento, el arquitecto italiano dispuso dos torres que visualmente compensaban la diferencia de altura que esta llevaba sobre el resto de las casas y a su vez servían de filtro intermedio para resaltar y agrandar la plaza. El Barroco gustaba utilizar estos ardides ópticos para magnificar frentes o espacios demasiado exiguos. En la restitución redibujada en tres dimensiones que se hace aquí, se han colocado otras dos torres en las esquinas del desconocido lado este. Es una mera hipótesis, inducida por el desarrollo y cumplimiento de las leyes del Barroco que Torelli manejaba con acierto. Se devuelve así una cierta centralidad a la plaza, neutralizando una orientación, demasiado contradictoria, hacia el este, en contra de la dominante norte sur que prevalecía en la ciudad y que era la apuesta de la primera versión presentada que al final se rechazó. Joaquín de Ordóñez (Sn Sebastian en 1761, Descripción...1900, p.24) habla de las dos torres de la parte de Poniente, "...dos torres uniformes muy bien hechas y perfectas en el todo, en una está una campana con la que se convoca á los vecinos...". El mismo Ordóñez se maravilla de que se hayan dispuesto "... sólo tres balcones que dan vuelta á toda la plaza...". ¿Existía una continuidad de los balcones, mediante arcadas, en las esquina de la parte oriental de la plaza, tal como lo parece indicar literalmente Ordóñez o es un efecto literario y metafórico de su prosa? Como es imposible dilucidarlo, nos sea permitido escoger, para la restitución, la solución mas elegante y acabada, es decir la de los tres únicos balcones en U, la solución la más arquitectónica, y porque no, la más poética.

Ugartemendía resolvió los encuentros de las cuatro esquinas con arcadas, solo en la planta baja. Quizás quería compensar el efecto grandilocuente de las columnas del Ayuntamiento uniéndolo mediante dichas arcadas al resto de las edificaciones de la plaza. Pero el resultado no es del todo convincente, los arcos de la Casa Consistorial desmerecen y aparecen todavía más escasos. La unión resulta un poco forzada y desencajada. Torelli se abstuvo sabiamente de conectar arquitecturas diferentes y prefirió obtener el equilibrio visual mediante sus dos torres esquineras.

Queda también la duda del tratamiento del suelo y pavimento de la plaza, un simple encintado o más bien un rehundido con gradas, que se inundaba en días de tormenta, tal como lo criticaba Ugartemendia. Esta interpretación sería una explicación más plausible que una simple depresión, incomprensiblemente no resuelta por Torelli, justo en ese lugar, en el centro del casco. Existe el ejemplo en el que se pudo inspirar Torelli, de la solución del rehundido con gradas de la plaza del Campidoglio, aunque de forma elíptica y no rectangular. El rebaje del centro de la plaza, otro procedimiento del Barroco para darle a esta un mayor relieve, podría haber servido para delimitar el espacio de los festejos, facilitando la contemplación y el disfrute de estos, pero también para apartar las aguas de lluvia de los soportales. En un acta de la junta de obras de la reconstrucción de San Sebastián, del 26 de Noviembre de 1816, se indica, a proposito de unas obras, que "...las arenas y escombros que salgan se conducirán a las partes bajas de la Plaza Nueva...". 
Con este primer relleno, empezaría el cambio de cotas que Ugartemendia impuso a la Plaza, con una subida de dos a tres metros, y que generalizó, con variaciones, a todo el casco intramuros. Ni que decir que suprimió el rehundido y las torres de esquina, cosas que casaban mal con el ayuntamiento del que fue coautor con Silvestre Pérez.

\section{6 -CONCLUSIÓN.}

La Plaza Nueva de San Sebastian fue ejemplar en más de un sentido. Obviando la justeza y belleza de su diseño que, a pesar de sus reducidas dimensiones, hizo que la considerasen una de las más hermosas de la península e incluso de las más grandes, según Ordóñez, tan grande era el efecto visual que producía. Se la podría considerar pionera en materia de urbanismo tanto en el aspecto formal como en el político, el social y el económico. Hasta entonces las plazas se formaban en espacios intersticiales, entre núcleos urbanos o exteriores a estos. Por economía de espacio la villa medieval no disponía de plazas mayores. Incluso en la propia Roma el foro, "forum", proveniente de foris, fuera, era, antes de convertirse en centralidad, un espacio exterior a la "urbis". Descartando las que se crean enmarcadas en villas y ciudades de nueva fundación, la mayoría de las plazas mayores españolas y europeas se originan en espacios de mercado exteriores a las murallas y en un momento dado el monarca o sus representantes deciden regularizar el lugar cuando este es absorbido por la ciudad. Para ello se efectúan algunos derribos para permitir alineaciones y nivelaciones. Muchas veces los incendios conducen a plantearse la reconstrucción de la plaza en términos más ordenados y ambiciosos. Es el caso de la Plaza Mayor de Madrid, primero un lugar exterior para los puestos de mercado, que tiene un largo proceso edificatorio a partir del encargo hecho por Felipe II a Juan de Herrera en 1580 y que se reconstruye varias veces tras sendos incendios. Es el caso de la Plaza Mayor de Valladolid cuyo proyecto, impulsado por el mismo Felipe II, se concreta tras un incendio en 1561. Unos años más tardía que la de San Sebastián, la Plaza Mayor de Salamanca, diseñada por Alberto Churriguera, sigue el mismo proceso, teniéndose que solicitar a los vecinos para que reconstruyan sus casas, adaptándose a las nuevas alineaciones, y cedieran terrenos si falta hiciese. A veces, se recurrió a la expropiación y a la propiedad pública de las viviendas, como en San Sebastián, pero con la diferencia de que se hizo puntualmente y de manera forzada. Al establecer comparaciones, la Plaza Nueva donostiarra se distingue sobremanera de todos estos ejemplos emblemáticos.

Primero, porque se vacía y actúa en el centro consolidado de una ciudad sin que medie incendio ni desastre alguno, para insertar un espacio y un conjunto edificado planificados ad hoc. El diseño, racional, igualitario y repetitivo, tanto de las fachadas como de las plantas, será ejecutado al unísono en poco tiempo, en menos de cinco años, contrastando con los demás ejemplos aquí presentados que se alargaron decenas de años, o más, y que consiguieron su uniformidad paulatinamente, y no de una manera rápida y total.

Segundo, porque la propiedad de la totalidad de las casas de la plaza es pública, como público es el proceso constructivo. La Plaza Nueva será uno de los más preciados "propios" de la ciudad de San Sebastián. La Ciudad gestionaba no solo la renta de las viviendas, sino también la de los bajos con sus cabañas y soportales. Explotaba la plaza como centro de espectáculos, en parte taurinos, con el alquiler de los balcones y demás entablados o gradas provisionales dispuestos delante de los arcos, y la correspondiente tasación de comidas y bebidas, "carnes y cueros" que se vendían a los asistentes. Sólo se compartía la propiedad de la Casa consistorial con el Consulado, organismo, íntimamente ligado a los entresijos del poder municipal, al representar a los armadores y grandes comerciantes donostiarras.

Tercero, porque el Ayuntamiento de San Sebastian planteó y planificó la operación de la Plaza Nueva por iniciativa propia, sin consultar el Poder Real, en contra de los usos y procedimientos de la época que hacían obligatorio el permiso Real, cuando no era el propio Rey, o sus representantes, quienes tomaban las decisiones. El poder Real decretó autos suspensivos, ineficaces, y finalmente ratificó los hechos consumados. Eso si, subrayando la obligación de que la propiedad del conjunto sea pública, obligación que la Ciudad ya esgrimió previamente para justificar y facilitar las expropiaciones y la futura gestión de la plaza.

\section{BIBLIOGRAFIA}

(1802). Diccionario Geográfico histórico de España. Madrid

LLAGUNO y AMIROLA. (1829-1977). Noticias de los Arquitectos y Arquitectura de España... Madrid

CAMINO y ORELLA, J.A. (1892-1963). Historia de San Sebastián. S.S. Ayuntamiento. 
ORDÓÑEZ, J. (1900). San Sebastian en 1761, Descripción. S.S. Ayuntamiento HEGEMANN W. (1922-1992), Arte Civil, Caja de Arquitectos

LINAZASORO, J.I. (1978). Permanencias y arquitectura urbana. Barcelona G.G.

GARCIA FERNANDEZ J.L., IGLESIAS ROUCO L.S., La Plaza en la Ciudad, H.BLUME AVELLANOSA CARO, T. (2003). Plazas Mayores de España. Ed.Rueda.

Archivo Municipal de San Sebastián, Archivo General y Archivo Histórico de Protocolos de Gipuzkoa. Archivo General de Simancas, Archives de la Défense Vincennes

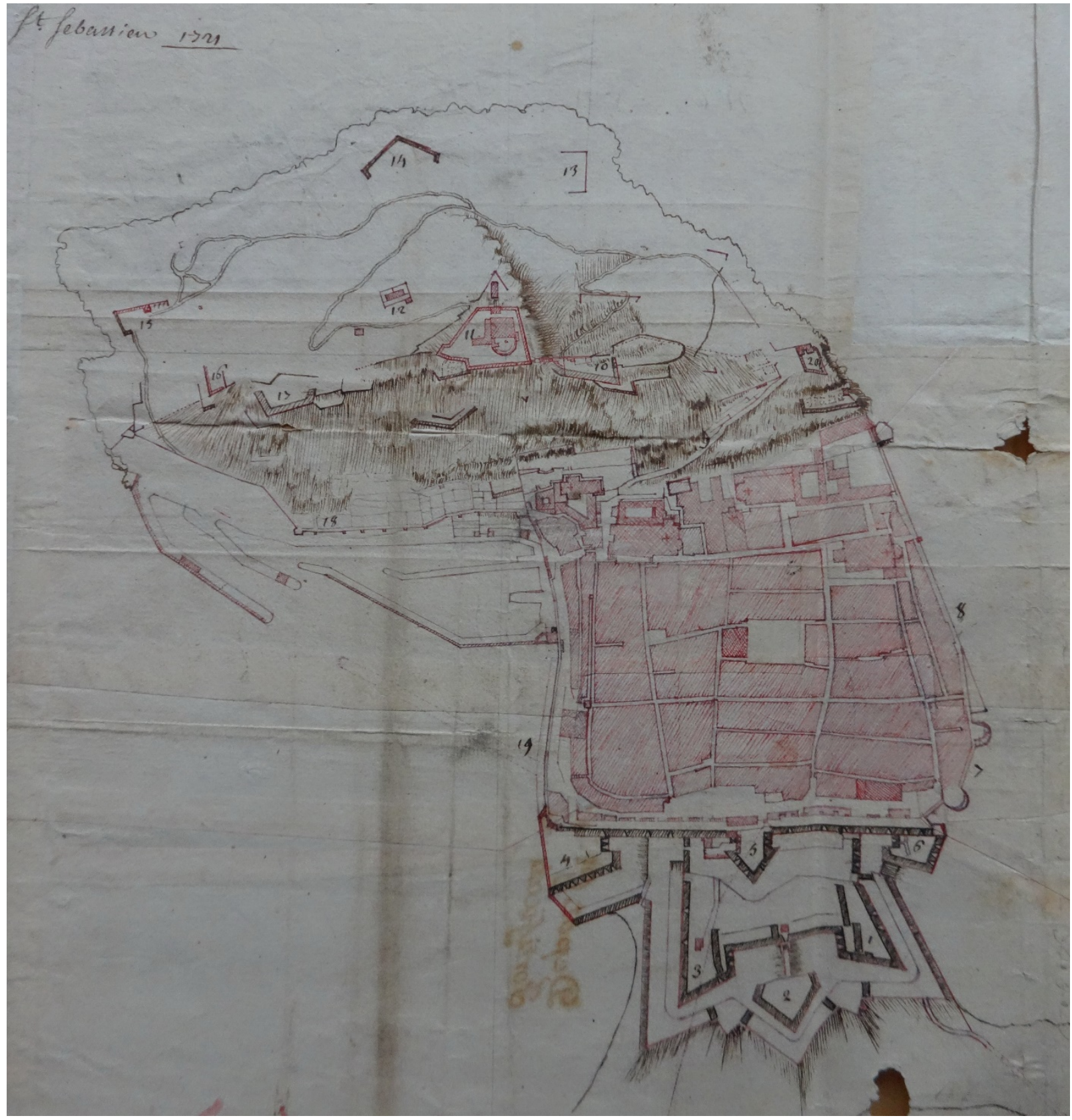

Fig.1 - 1721 -Primera referencia de la Plaza Nueva y su Ayuntamiento -Archives de la Défense, Vincennes. 


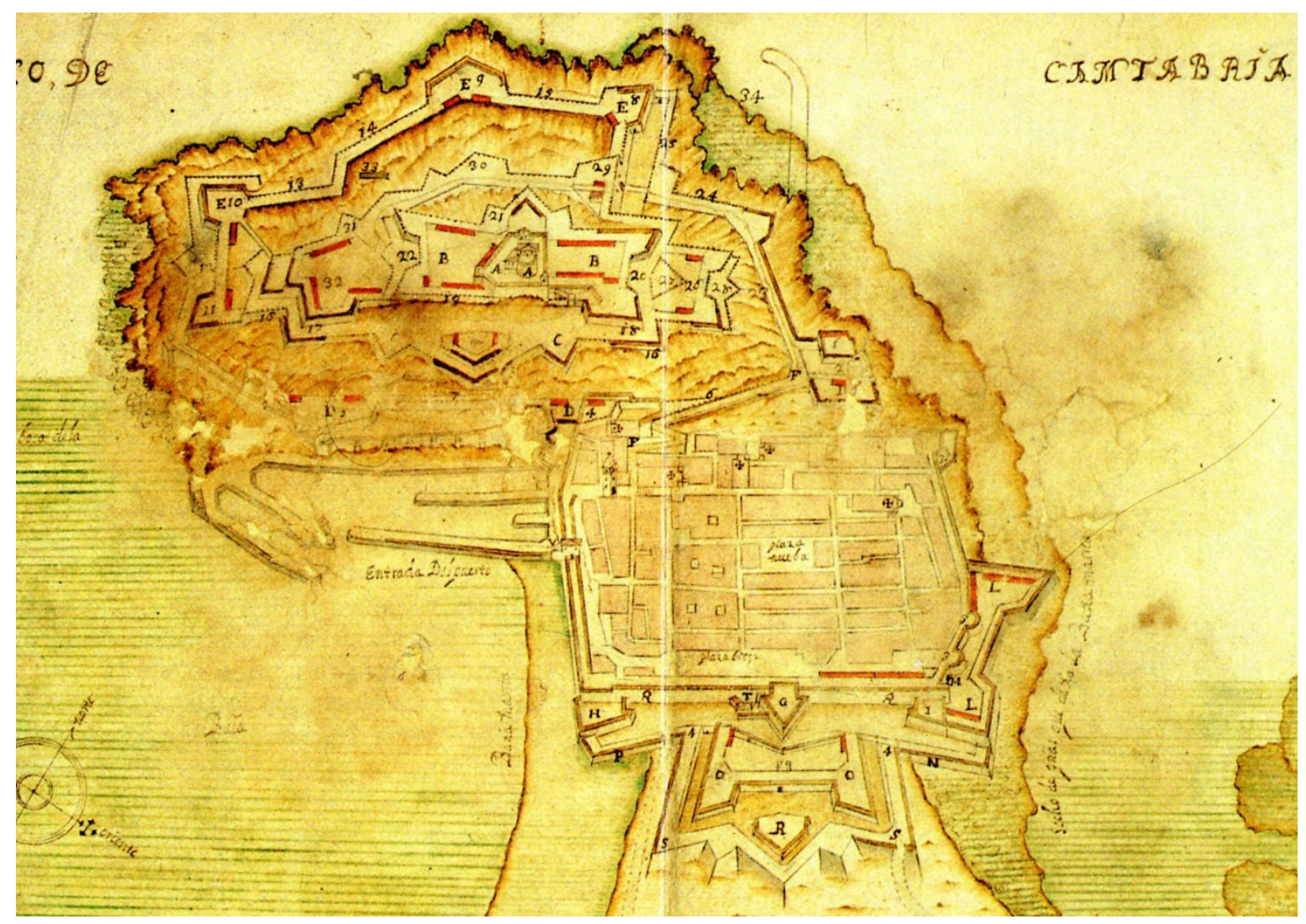

Fig.2 - 1723 -La Plaza Nueva señalada en una Planta de San Sebastián dibujada por Hércules Torelli. - A.G.Simancas.

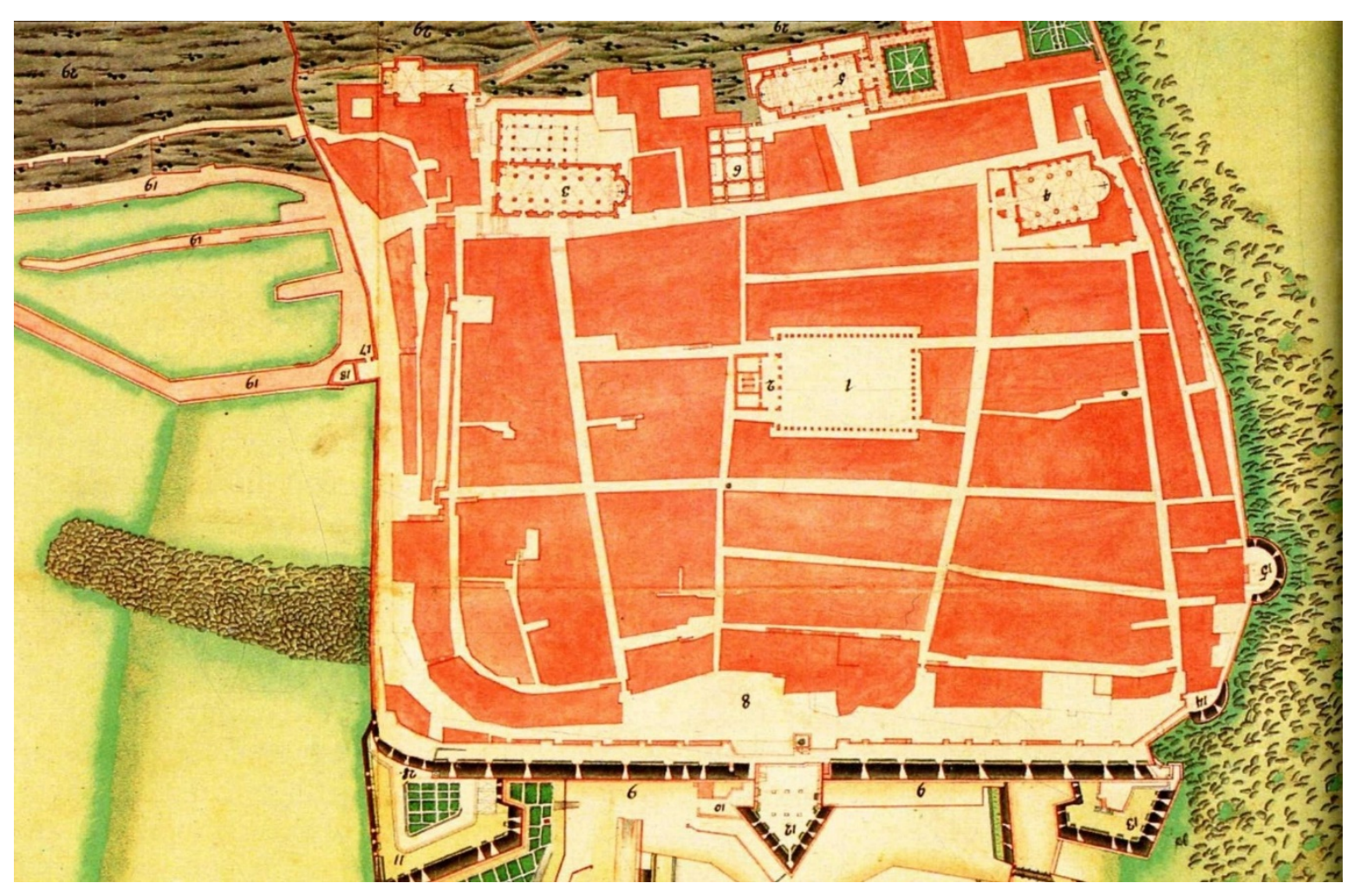

Fig.3 - 1744 -La Plaza Nueva en un Plano dibujado por De Frosne - A.G.Simancas. 


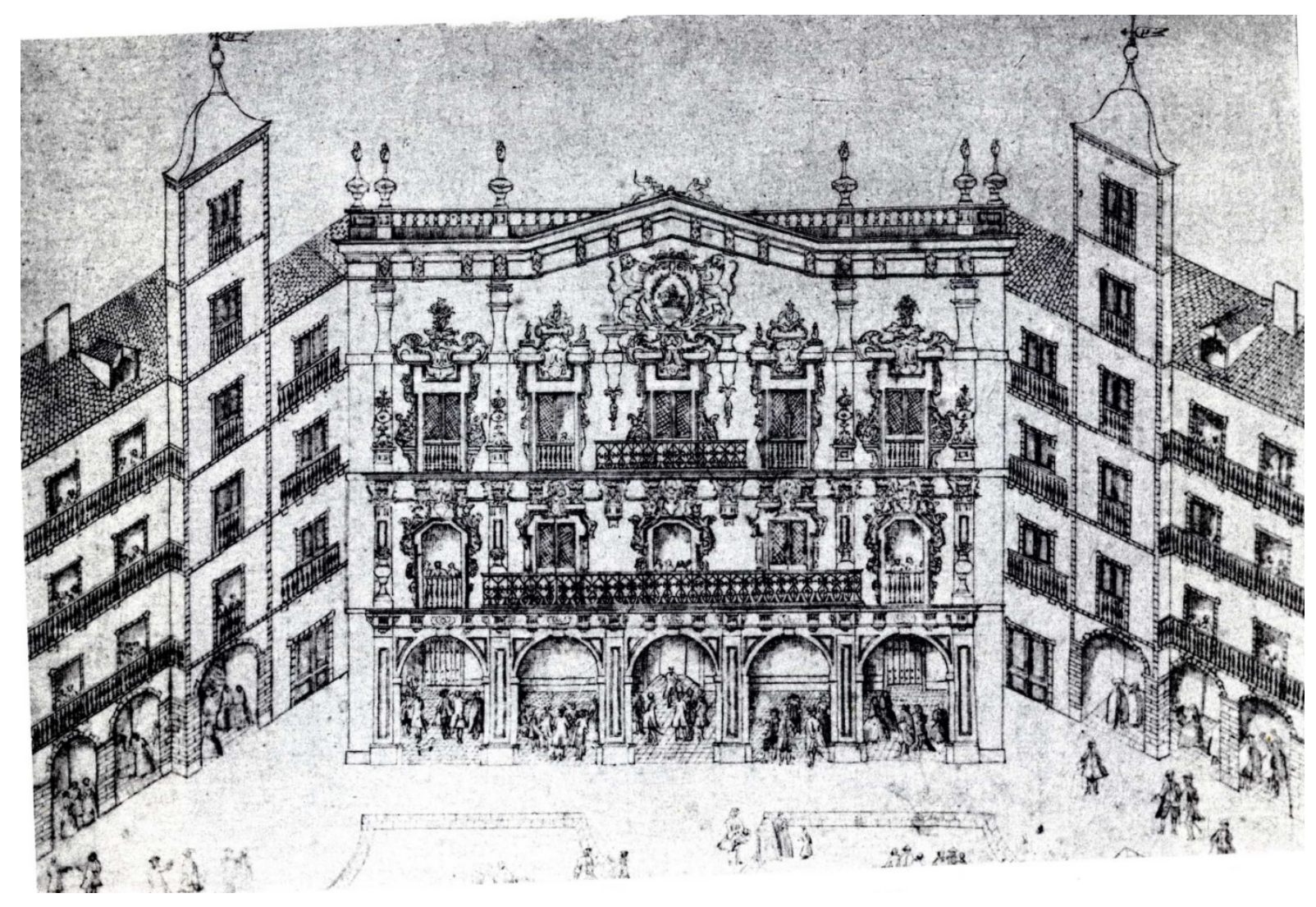

Fig.4 - El Ayuntamiento de Hércules Torelli, dibujo (retocado) -Museo de San Telmo Donostia-San Sebastián.

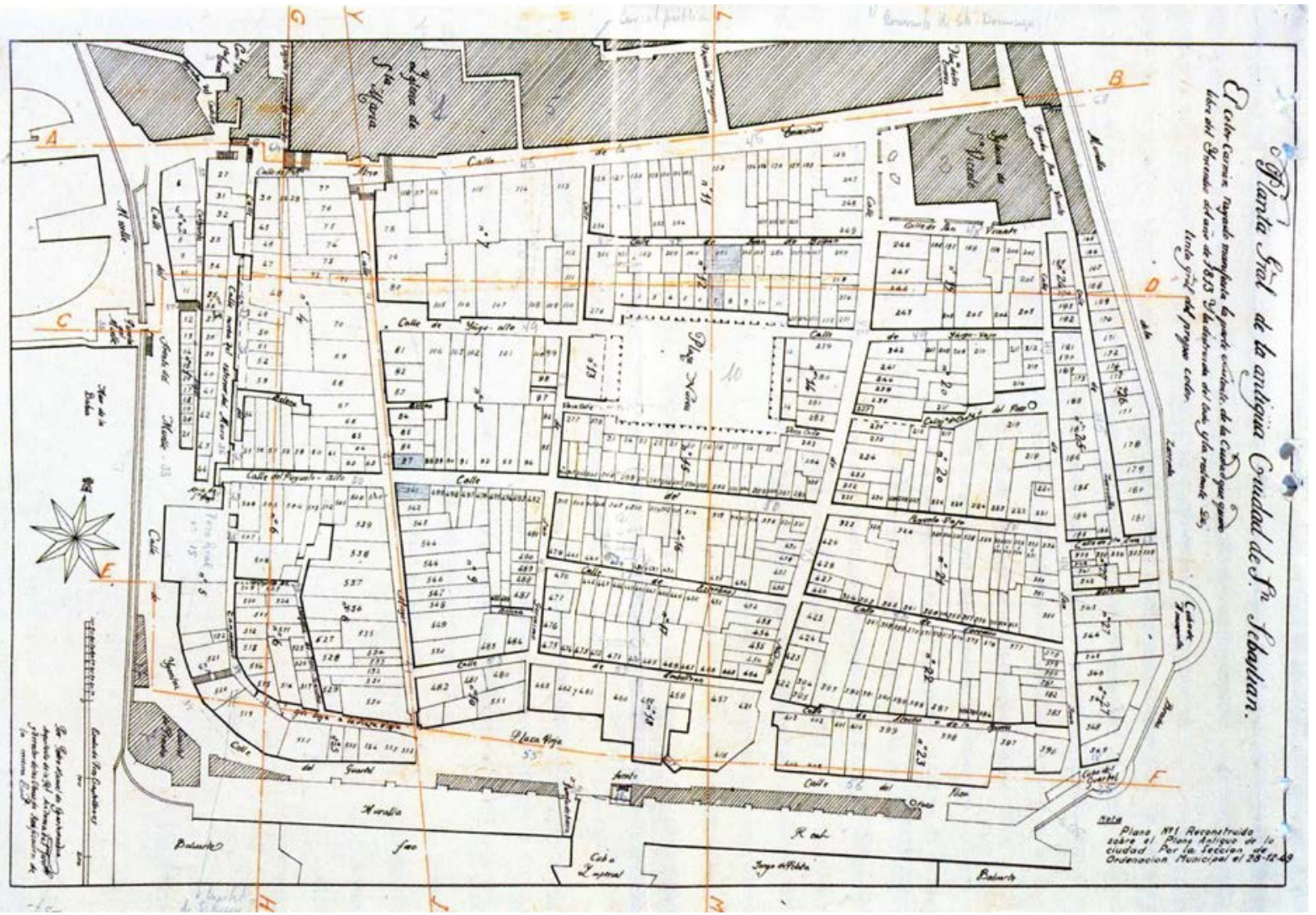

Fig.5 - 1814 - Parcelario de Ugartemendía redibujado en 1949.-Ayuntamiento de Donostia-San Sebastián. 


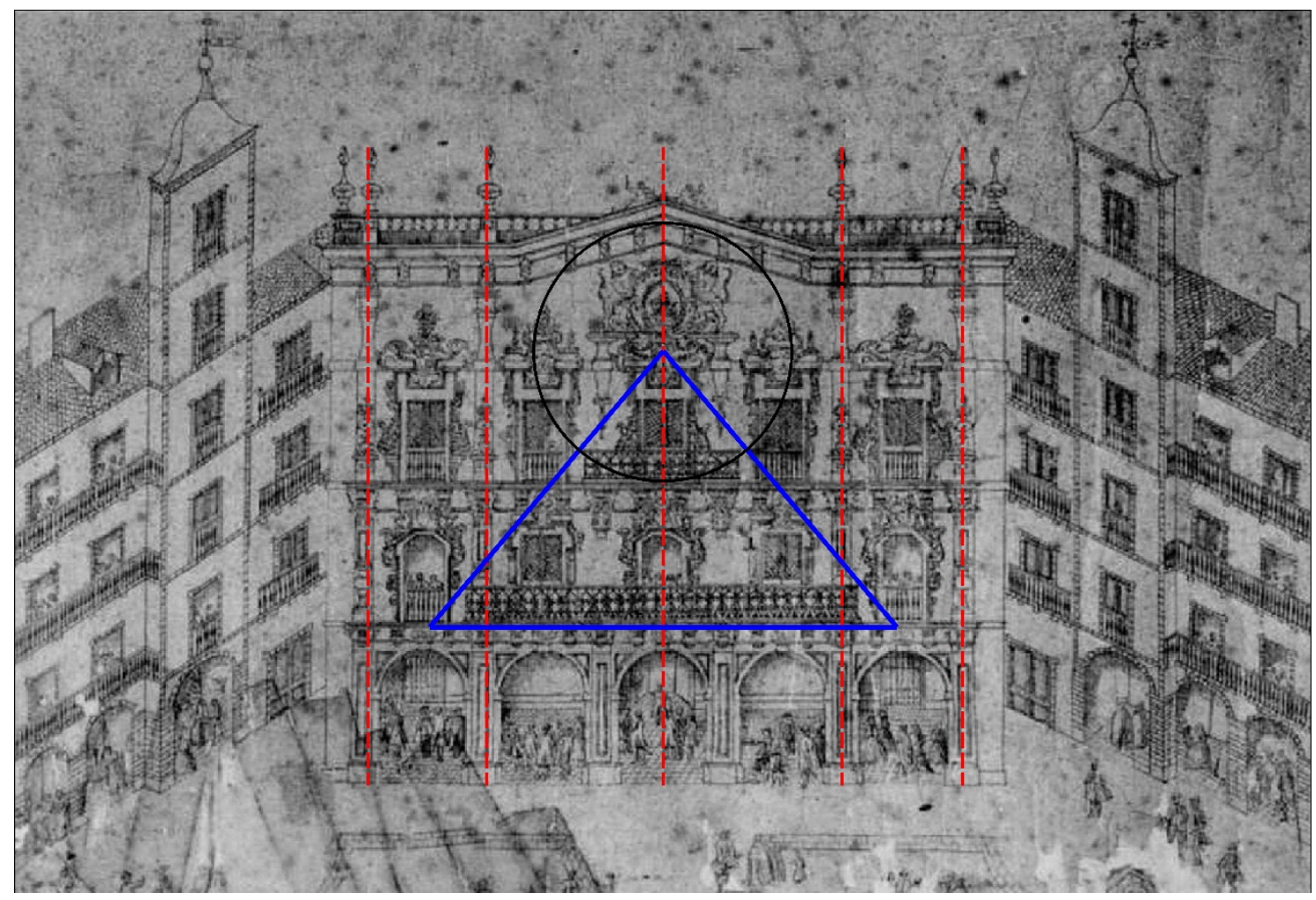

Fig.6 - Una sutil composición de fachada (sobre el dibujo original) - esquema del autor.

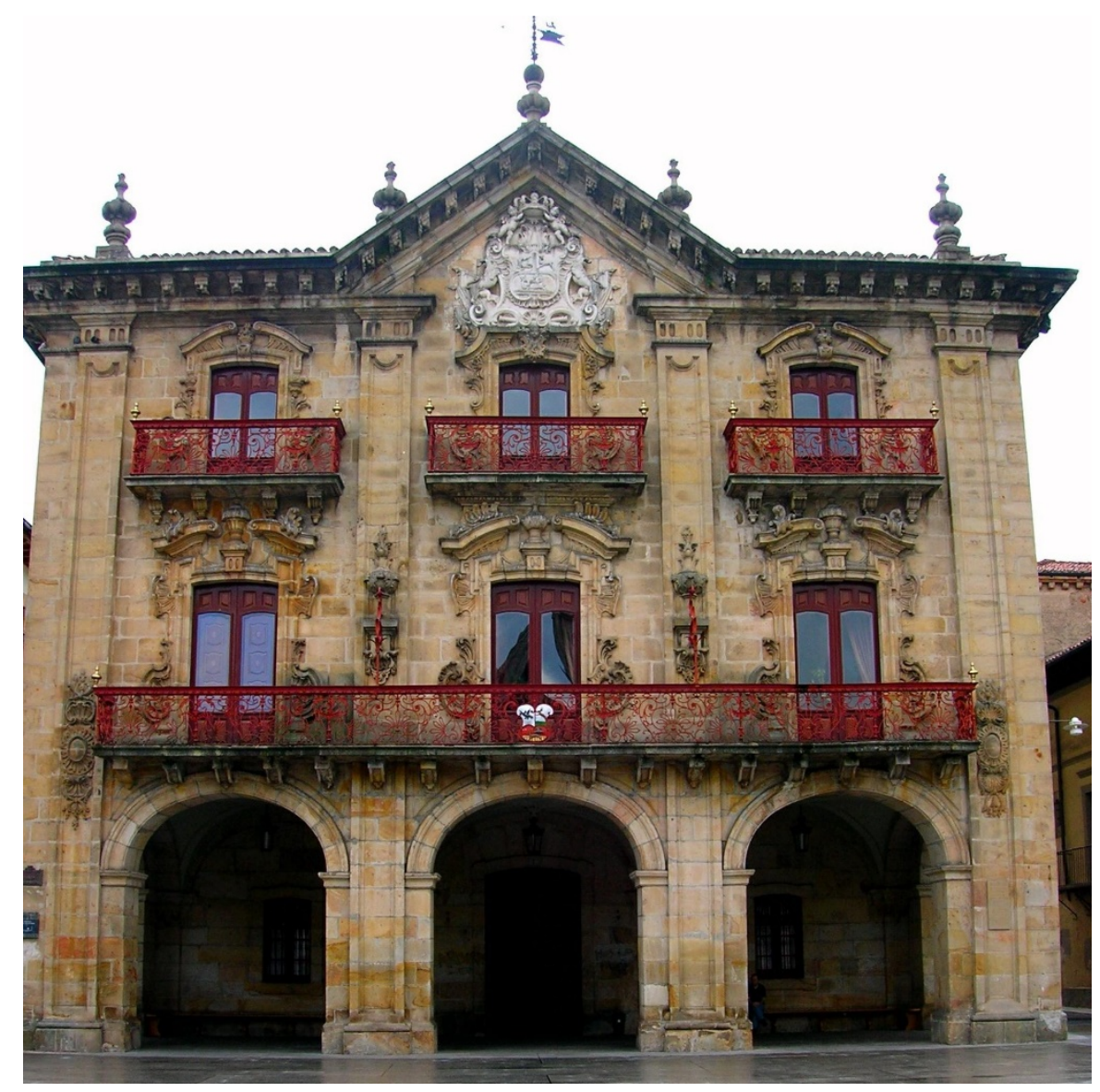

Fig.7- Ayuntamiento de Oñati de Martín Carrera, hoy. 


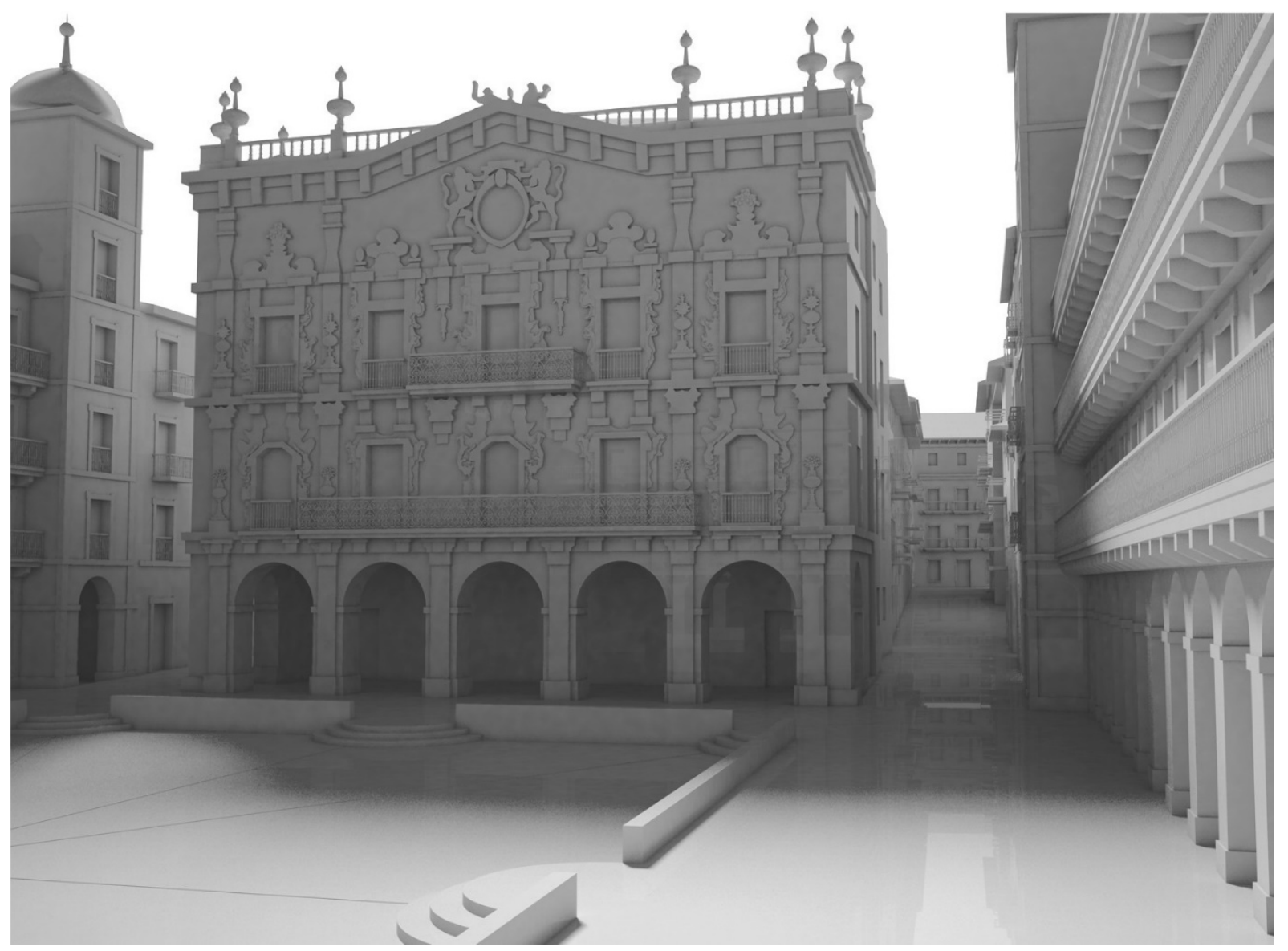

Fig.8 - Ayuntamiento de San Sebastián de Hércules Torelli 1723-1813, restitución del autor.

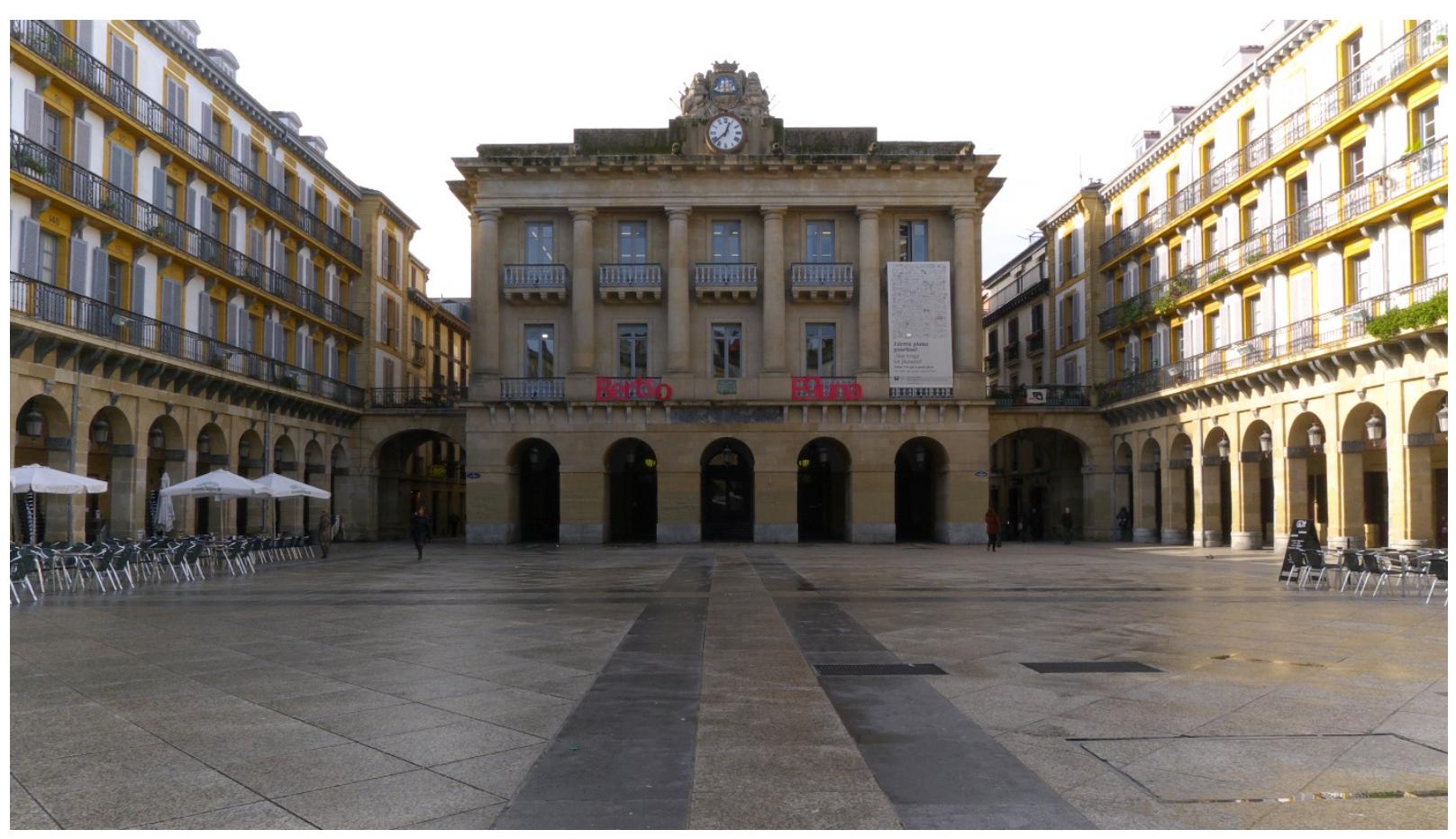

Fig.9 - Plaza de la Constitución y Ayuntamiento de Silvestre Pérez y Ugartemendía, hoy. 


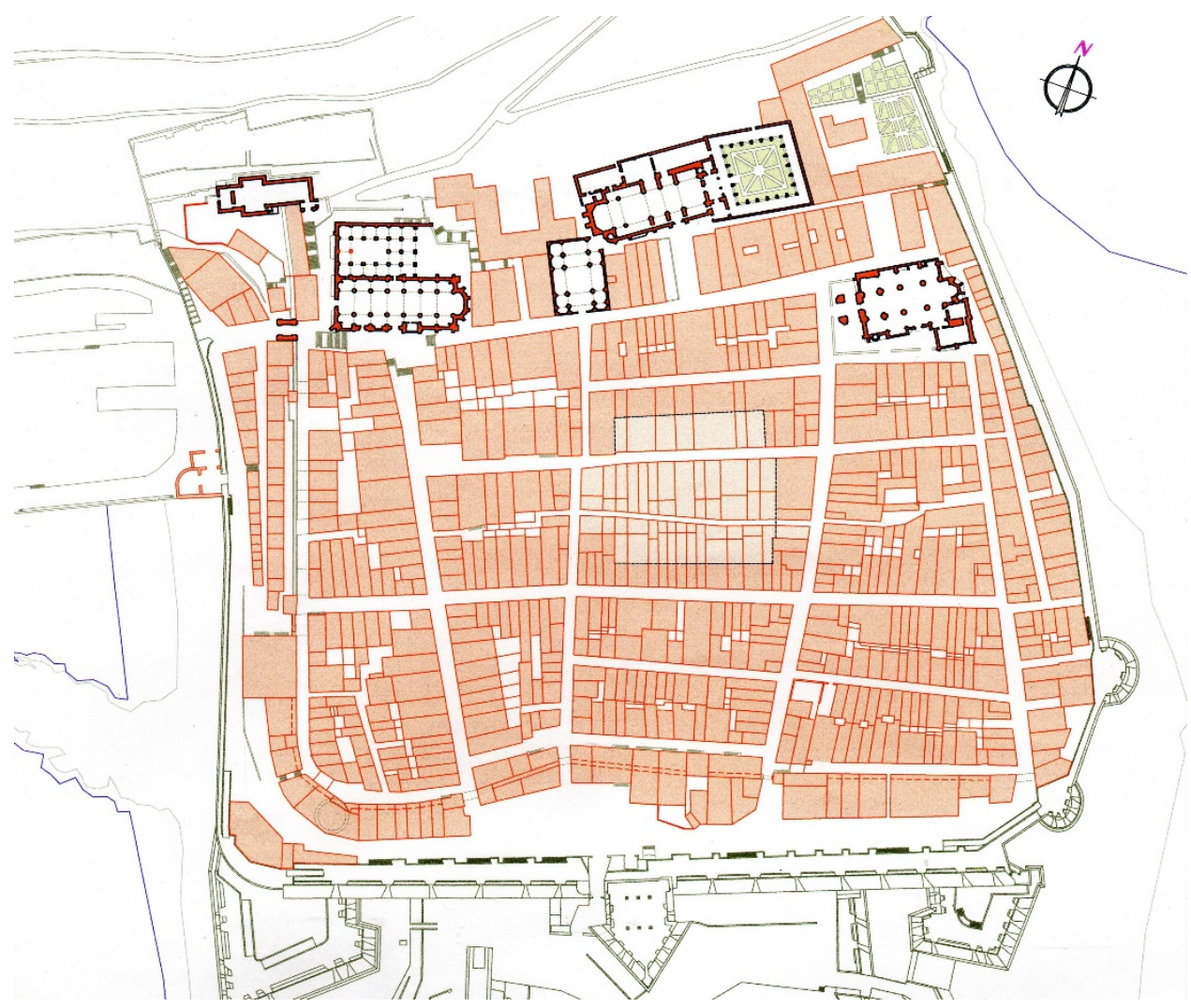

Fig.10 - San Sebastián en 1715, mostrando la parte intervenida, reconstitución hipotética del autor.

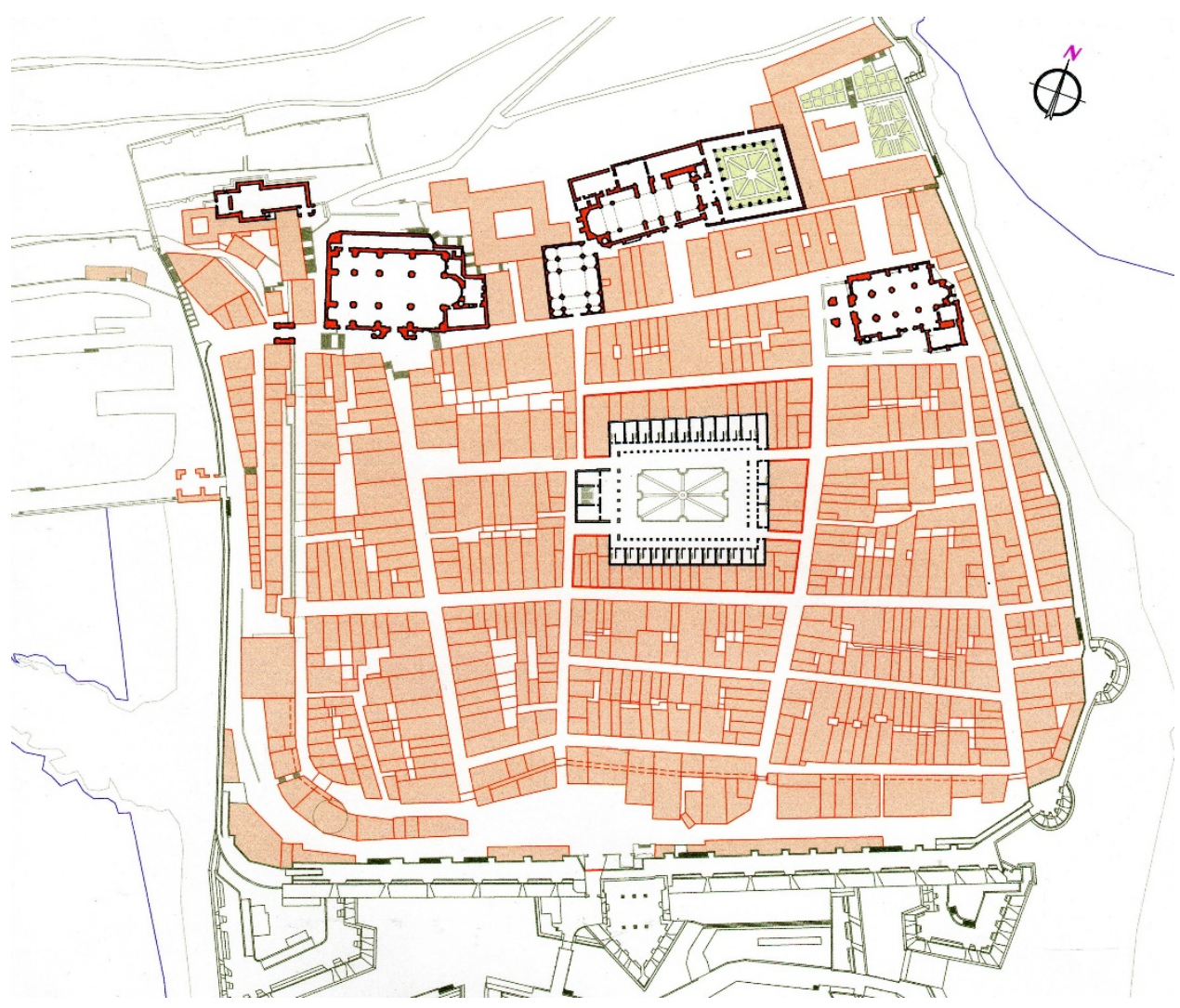

Fig.11 - San Sebastián en 1800, reconstitución hipotética del autor. 


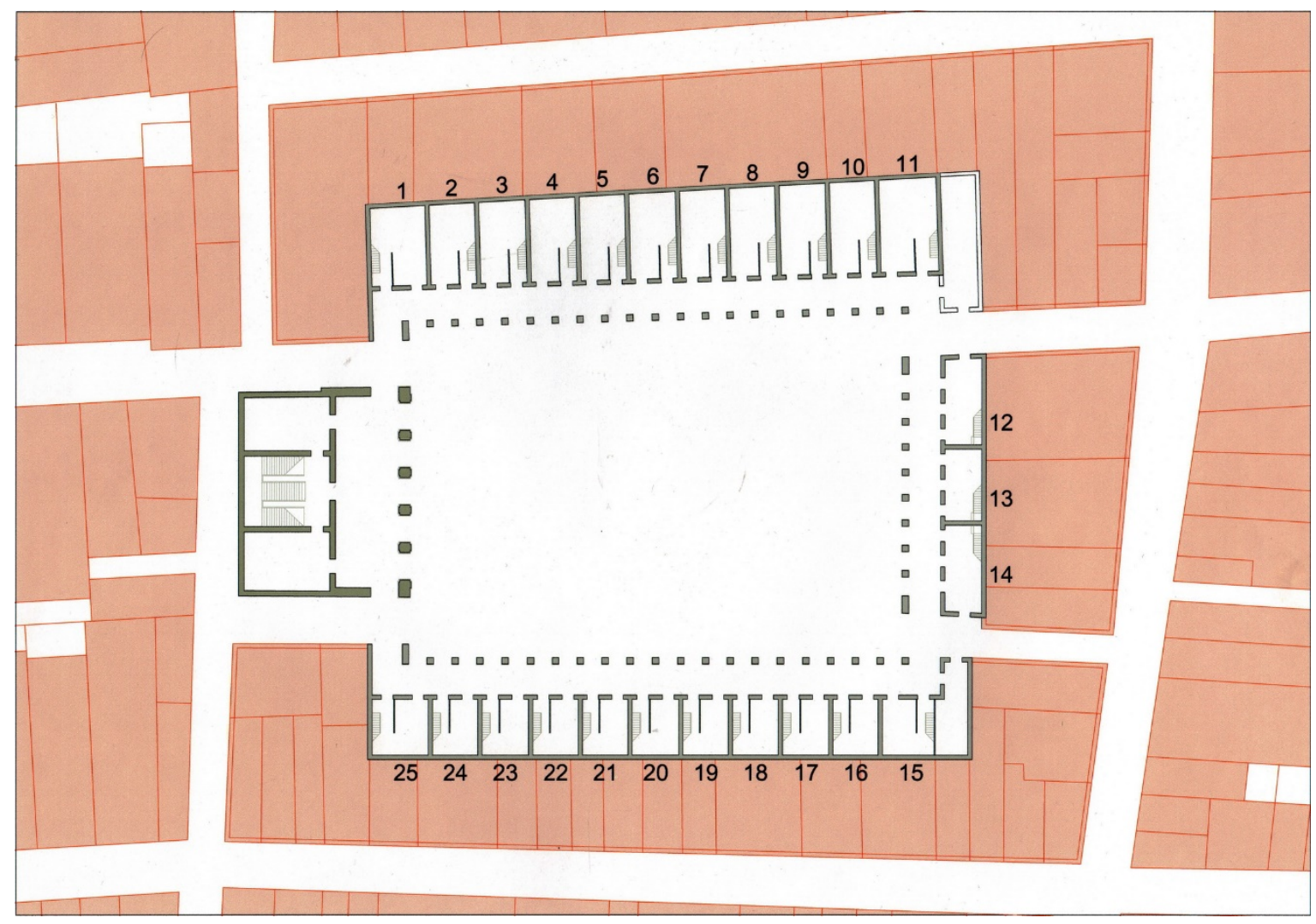

Fig.12 - Planta Baja de la Plaza Nueva de San Sebastián, reconstitución hipotética del autor.

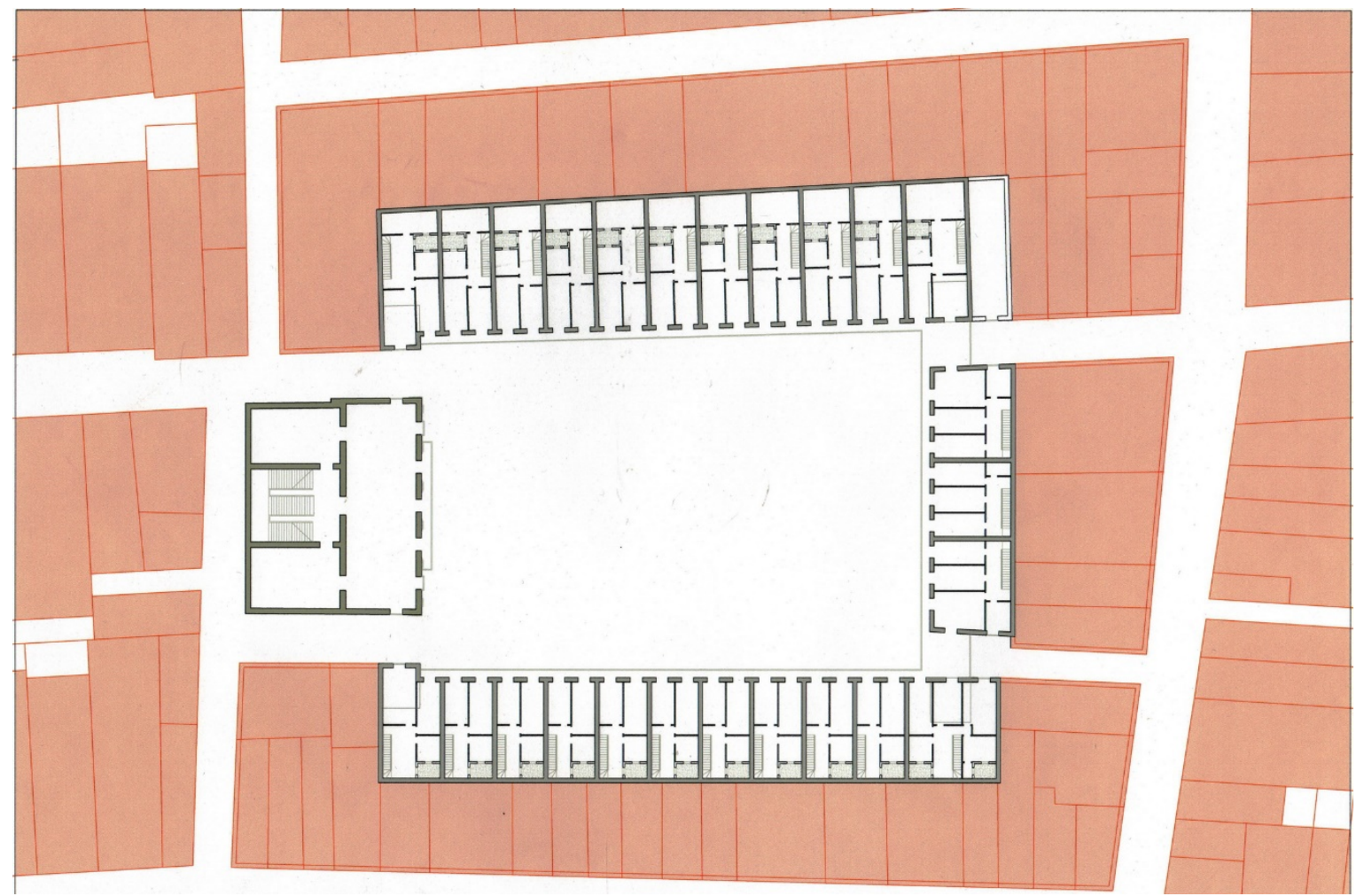

Fig.13 - Planta Tipo de la Plaza Nueva de San Sebastián, reconstitución hipotética del autor. 


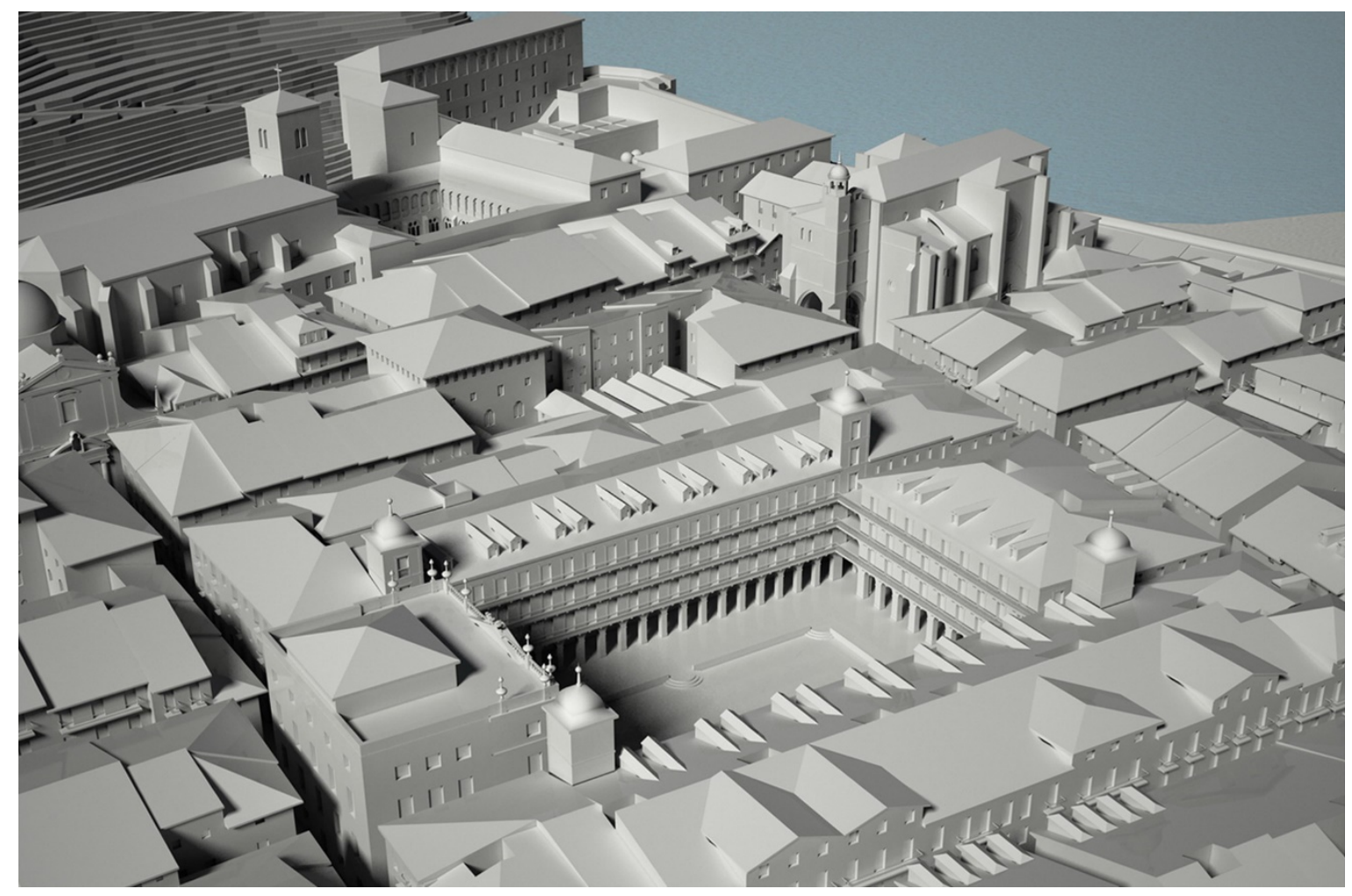

Fig.15 - La Plaza Nueva inserta en el tejido urbano de San Sebastián, reconstitución hipotética del autor.

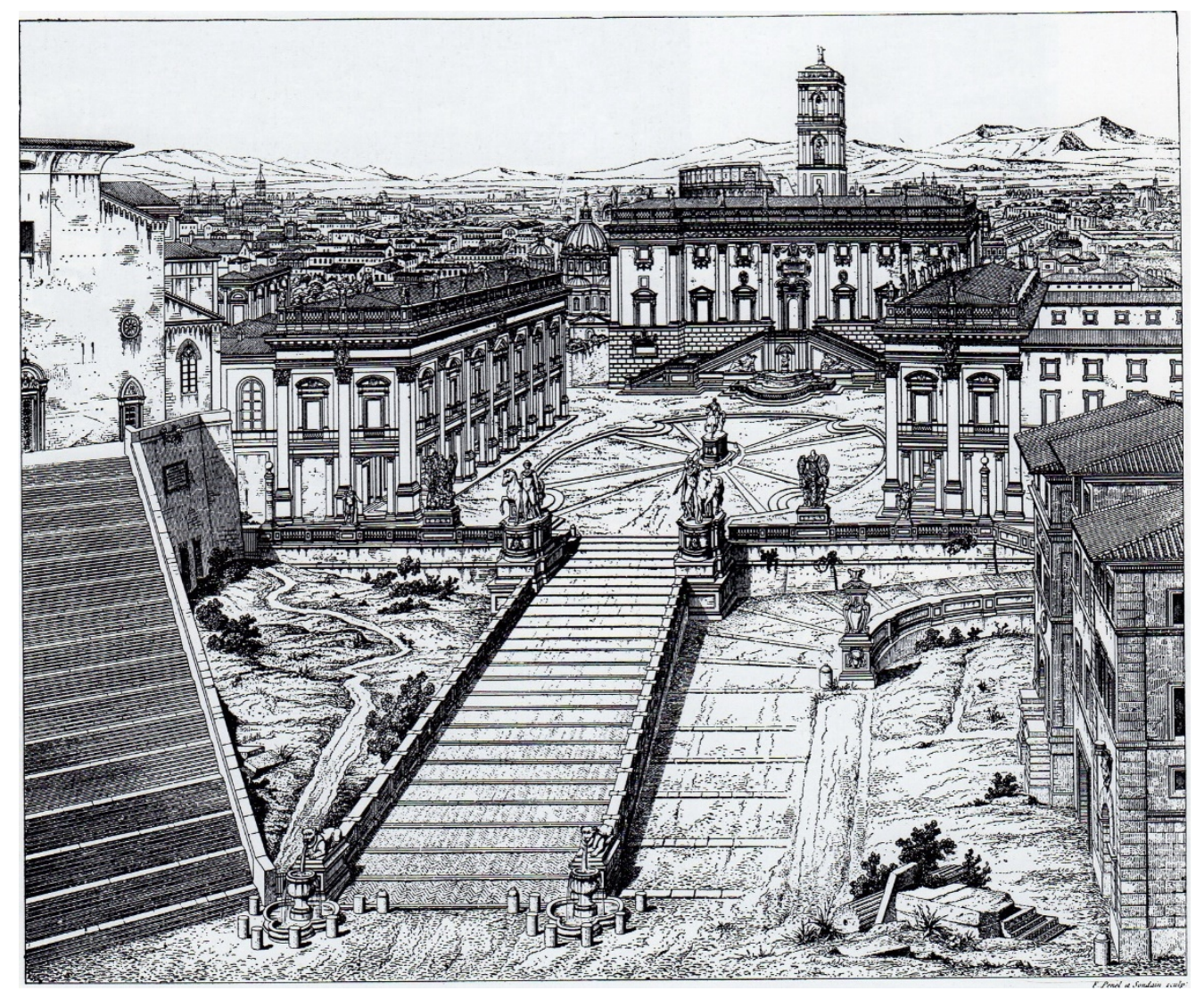

Fig.16 - Plaza del Campidoglio de Roma a principios del XIX, dibujo de Letarouilly. 